\title{
Inflammatory changes, recovery and recurrence at COPD exacerbation
}

\author{
W.R. Perera*, J.R. Hurst*, T.M.A. Wilkinson*, R.J. Sapsford*, H. Müllerova\#, \\ G.C. Donaldson* and J.A. Wedzicha*
}

ABSTRACT: Chronic obstructive pulmonary disease (COPD) exacerbations are associated with increased airway and systemic inflammation, though relationships between exacerbation recovery, recurrent exacerbation and inflammation have not been previously reported. In the present study, inflammatory changes at COPD exacerbations were related to clinical nonrecovery and recurrent exacerbations within $\mathbf{5 0}$ days.

Serum interleukin (IL)-6, C-reactive protein (CRP), sputum IL-6 and IL-8 were measured in 73 COPD patients when stable, at exacerbation and at 7, 14 and 35 days post-exacerbation.

In $23 \%$ of patients, symptoms did not recover to baseline by day 35 . These patients had persistently higher levels of serum CRP during the recovery period. A total of $22 \%$ of the patients who had recurrent exacerbations within $\mathbf{5 0}$ days had significantly higher levels of serum CRP at day 14 , compared with those without recurrences: $8.8 \mathrm{mg} \cdot \mathrm{L}^{-1}$ versus $3.4 \mathrm{mg} \cdot \mathrm{L}^{-1}$. Frequent exacerbators had a smaller reduction in systemic inflammation between exacerbation onset and day 35 compared with infrequent exacerbators.

Nonrecovery of symptoms at chronic obstructive pulmonary disease exacerbation is associated with persistently heightened systemic inflammation. The time course of systemic inflammation following exacerbation is different between frequent and infrequent exacerbators. A high serum C-reactive protein concentration 14 days after an index exacerbation may be used as a predictor of recurrent exacerbations within 50 days.

KEYWORDS: Chronic obstructive pulmonary disease, exacerbation, inflammation

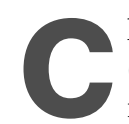
hronic obstructive pulmonary disease (COPD) is characterised by episodic increases in respiratory symptoms, which are called exacerbations. These episodes contribute considerably to the increased morbidity, mortality and healthcare costs associated with this condition. Some patients are prone to frequent exacerbations and these patients have worse health status [1], greater limitation of their daily activities [2] and faster disease progression [3, 4].

COPD exacerbations are associated with increases in airway and systemic inflammation [5-11] that are heterogeneous and probably related to the aetiology of the exacerbation [5, 12]. However, no detailed information is available on the time course of airway and systemic inflammation during exacerbations, and how these changes relate to clinical indices of exacerbation severity, including the length of recovery. The current authors have previously shown that patients with frequent exacerbations have increased airway inflammation in the stable state [5]. It has also been demonstrated that nonrecovery of symptoms and peak flow at 35 days after the onset of the exacerbation occurs in $\leqslant 25 \%$ of patients [13].

Exacerbations have a tendency to cluster in an individual as demonstrated by studies of patients hospitalised with severe COPD exacerbations. Such studies have shown that after the index exacerbation, patients are at increased risk of readmission and one study showed that $34 \%$ of patients were readmitted with a recurrent exacerbation in the 3 months following their discharge [14-17]. Frequent readmissions with COPD exacerbations have been highlighted as an independent risk factor for increased mortality [15]. It is currently unknown whether these recurrent exacerbations are associated with persistence of a heightened inflammatory status or are perhaps related to nonrecovery of the index exacerbation.

The present authors hypothesised that persistent exacerbation symptoms may be related to a heightened inflammatory status, and that clinical nonrecovery and recurrence of exacerbations
AFFILIATIONS

*Academic Unit of Respiratory

Medicine, University College London, London and

\#Epidemiology, GlaxoSmithKline, Greenford, UK.

CORRESPONDENCE

J.A. Wedzicha

Academic Unit of Respiratory

Medicine

Royal Free \& University College

Medical School

Rowland Hill Street

Hampstead

London

NW3 2PF UK.

Fax: 442074726141

E-mail: j.a.wedzicha@medsch.ucl.

ac.uk

Received:

July 122006

Accepted after revision:

October 302006

SUPPORT STATEMENT

This study was funded by the Joint

Research Board of the Special

Trustees of St Bartholomew's

Hospital London and an unrestricted educational grant from

GlaxoSmithKline.

\section{STATEMENT OF INTEREST}

Statements of interest for J.A. Wedzicha and $\mathrm{H}$. Müllerova can be found at www.erj.ersjournals.com/ misc/statements.shtml 
would relate to nonrecovery of the inflammatory response. Therefore, a prospective study in a well-characterised cohort was performed, in which airway and systemic inflammation were assessed in the stable state, at exacerbation onset prior to treatment and throughout the recovery period at days 7,14 and 35. Furthermore, the relationship between these airway and systemic markers was assessed at exacerbation, with recurrent exacerbations occurring within 50 days of the index event. Finally, the evolution of airway and systemic inflammatory markers in patients stratified according to their exacerbation frequency was studied.

\section{METHOD}

\section{Patient recruitment}

In total, 73 patients were recruited from the London COPD study. This is a rolling cohort of patients used to prospectively investigate the mechanisms of COPD exacerbations [1, 2, 4-6, 10-13]. COPD was defined as a post-bronchodilator forced expiratory volume in one second (FEV1) to forced vital capacity ratio $<70 \%$ and a $\beta_{2}$-agonist reversibility on predicted FEV1 of $<15 \%$ or $200 \mathrm{~mL}$. Patients with a history of other significant respiratory diseases were excluded, as were those unable to complete daily diary cards. Patients were recruited when stable, $\geqslant 6$ weeks from their last exacerbation. At recruitment, patients' daily respiratory symptoms, smoking history, COPD exacerbation history and drug history were recorded. Height and weight were measured, in addition to baseline lung function using a rolling seal spirometer (Sensor Medic Corp, Yorba Linda, CA, USA). Reversibility to $\beta_{2^{-}}$ agonists was measured after inhaling $400 \mu \mathrm{g}$ salbutamol from a metered-dose inhaler via spacer. Partial pressures of arterial oxygen and carbon dioxide were measured on arterialised ear lobe blood gases (Model 278 Blood Gas Analyser; CibaCorning, Medfield, MA, USA). Patients also completed the St. George's Respiratory Questionnaire, which is a diseasespecific measure of health status [18].

The study was approved by the ethics committee of the East London and City Health Authority and all patients gave written informed consent. A group of 12 samples had been previously used for an analysis of the upper and lower airway at exacerbation, though time course and exacerbation recurrence was not addressed in the previous study [10] and all the current analyses are original.

\section{Patient follow-up and exacerbation}

All patients were asked to keep daily diary cards on which they recorded their morning post-medication peak expiratory flow rate (PEFR) with a mini-Wright peak-flow meter (Clement-Clarke International Ltd, Harlow, UK) and any increase in their daily respiratory symptoms. Patients were routinely followed up every 3 months in the research clinic, their diary cards were reviewed and spirometry was recorded. Patients were asked to contact the study team when they experienced any increase in their daily respiratory symptoms. They were generally seen within $48 \mathrm{~h}$ by a study physician, their symptoms were reviewed and the exacerbation was confirmed according to the symptomatic definition described later. Patients were sampled before starting any additional treatment for the exacerbation.

\section{Definition of baseline}

Baseline was defined as the median symptom score recorded on days 14 to 8 , prior to the onset of the exacerbation.

\section{Definition of exacerbation}

The diagnosis of an exacerbation was based on symptomatic criteria previously validated by the present authors' group against important outcome measures in COPD, including sputum inflammatory markers [5], rate of decline in lung function [4] and quality of life [1]. Increased dyspnoea, increased sputum volume and increased sputum purulence were called major symptoms; nasal congestion or discharge, sore throat and increased chest tightness, wheeze or cough were termed minor symptoms. An exacerbation was defined as any two major symptoms or one major and one minor symptom, present for at least 2 consecutive days, the first of which was called the day of onset of the exacerbation.

\section{Exacerbation severity}

Each symptom, major and minor, was binary coded as one (present or increased over baseline) or zero (absent or not increased) and then summed. This symptom score was calculated daily throughout the exacerbation. Exacerbation severity was assessed by using the increase in the total symptom score at onset of exacerbation and the percentage reduction in FEV1 compared with baseline.

\section{Recovery time}

The recovery time for symptoms was defined as the time from onset of the exacerbation to the day on which a 3-day moving average of the symptom score had returned to baseline. In 12 exacerbations the diary card data was incomplete and a recovery date could not be ascertained.

\section{Nonrecovered exacerbation}

A nonrecovered exacerbation occurs when the total symptom score had not returned towards baseline by day 35 after exacerbation onset.

\section{Recurrent exacerbation}

A recurrent exacerbation was defined in the present study as a second exacerbation, fulfilling the present criteria, occurring within 50 days of the index exacerbation. Symptoms from the first exacerbation must have recovered, as previously defined.

\section{Time to next exacerbation}

Time to next exacerbation was defined as the time between the onset of the index exacerbation and the onset of the next exacerbation. These data were collected from clinic visits and the daily diary cards. Data were available for $\leqslant 10$ months after the last sampled exacerbation.

\section{Exacerbation frequency}

The number of exacerbations experienced by each patient was determined and the median exacerbation frequency was calculated. The patients were then divided into two groups around the median exacerbation frequency: those above the median were called frequent exacerbators and those with an exacerbation frequency below the median were called infrequent exacerbators. 


\section{Patient sampling}

Patients were seen and sampled in the stable state, at exacerbation prior to treatment, and at 7, 14 and 35 days later. Pre-exacerbation baseline samples were not available in 12 patients and post-exacerbation samples were therefore employed; these were obtained a minimum of 42 days after the preceding exacerbation. At each visit, the patients' symptoms were documented, lung function was recorded, and sputum and serum were collected. Spontaneous sputum was used; when no spontaneous sputum was available, patients were induced according to the present authors' previously described methodology [19]. Of the sputum samples taken, $97 \%$ were spontaneous. The present authors have previously reported on the equivalence of induced and spontaneous samples for the assessment of airway inflammatory markers [19]. Sputum and blood samples were processed within $2 \mathrm{~h}$ of collection. Sputum was processed according to a previously described protocol [19], in the absence of dithiothreitol, and the supernatants were stored at $-80^{\circ} \mathrm{C}$. Peripheral venous blood $(7 \mathrm{~mL})$ was collected into a vacutainer tube and centrifuged at $671 \times g$ for $10 \mathrm{~min}$ at $4{ }^{\circ} \mathrm{C}$. The serum was separated and stored at $-80^{\circ} \mathrm{C}$ until later analysis. All exacerbations were treated with bronchodilators, antibiotics and/or oral steroids depending on the clinical severity of the episode, as judged by the attending physician.

\section{Measurement of inflammatory markers}

Sputum and serum interleukin (IL)-6 and sputum IL-8 were quantified using commercial sandwich ELISA kits (R\&D Systems, Abingdon, UK). Serum C-reactive protein (CRP) was measured using an Olympus luminometric analyser (Olympus Life and Material Science Europa GmbH, Hamburg, Germany). All the samples from each patient were measured in the same assay to reduce inter-assay variability. The limit of detection for serum and sputum IL-6 was $0.7 \mathrm{pg} \cdot \mathrm{mL}^{-1}$, for sputum IL-8 it was $10 \mathrm{pg} \cdot \mathrm{mL}^{-1}$, and for serum CRP it was $0.3 \mathrm{mg} \cdot \mathrm{L}^{-1}$. The reported levels of all the sputum mediators are 10 -fold dilutions by weight of the original sputum sample.

\section{Statistical analysis}

The Kolmogorov-Smirnov test of normality was applied. Normally distributed data were expressed as mean \pm SD and skewed data as median (interquartile range (IQR)). Skewed data were log-transformed to obtain a normal distribution. Comparisons between baseline and exacerbation data, and between the different exacerbation visits for symptoms, lung function parameters, and airway and systemic inflammatory markers, were analysed using a paired t-test, an unpaired t-test and Mann-Whitney U-tests as appropriate. Spearman's correlation was used to assess the relationships between changes in airway inflammation and recovery time, and between serum CRP at day 14 and time to next exacerbation. A Chi-squared test was used to compare exacerbation symptoms at the index and recurrent exacerbation. The percentage changes between baseline and the different exacerbation visits for each parameter were calculated.

A mixed linear regression model was used to study the changes in the time series of cytokine data, as this technique gives more flexibility to analyse within-patient changes, it accounts for a good level of correlation among the variables modelled, accommodates for missing data and restricts the bias towards zero. The mixed linear models with random effects compared the evolution of the time curve during the recovery phase of the exacerbation in two groups of patients separated by a binary trait (i.e. frequent versus infrequent exacerbators and recovered versus nonrecovered). First, the best fitting curve shape was determined individually for the different cytokines separated by a time variable. Then the best fitting curve model (using time, time-squared or time-cubed) was placed in the final model, in interaction with the binary trait to explain the response of the log-transformed cytokine. Finally, a visual output was produced from this modelling, using predicted values for each time point, expressed as a percentage of the value at exacerbation onset, accompanied by one SE. A probability of error of $\leqslant 5 \%$ was considered statistically significant.

\section{RESULTS}

\section{Patient characteristics}

In total, 73 exacerbation time courses were collected from 73 different patients; their baseline characteristics are reported in table 1, which demonstrates that the cohort have moderately severe disease with a mean FEV1 of $1.08 \mathrm{~L}$ or $45 \%$ predicted. The median (IQR) exacerbation frequency was 3.1 (2.0-4.2) per yr. There were no significant differences in the baseline characteristics between frequent and infrequent exacerbators, except for the exacerbation frequency itself. Median \pm SD FEV1 in frequent exacerbators was $1.10 \pm 0.53$ versus $1.05 \pm 0.41 \mathrm{~L}$ in infrequent exacerbators $(p=0.62)$.

\section{Exacerbation characteristics}

At exacerbation, patients were seen and sampled a median (IQR) of 2 (1-3) days after the onset of the exacerbation and before they started treatment. The total symptom score at exacerbation onset was 5 (4-6). The percentage change in FEV1 at exacerbation compared with baseline was $-5.05 \%(-15.02-$ $6.18 \%$ ). All exacerbations were treated exacerbations: $63 \%$ were treated with antibiotics and oral corticosteroids, $4 \%$ with steroids alone and $32 \%$ with antibiotics alone.

\begin{tabular}{|c|c|}
\hline \multirow[t]{2}{*}{ TABLE 1} & $\begin{array}{l}\text { Baseline characteristics of the } 73 \text { chronic } \\
\text { obstructive pulmonary disease patients ( } 39 \\
\text { males, } 20 \text { active smokers) }\end{array}$ \\
\hline & Mean \pm SD \\
\hline Age yrs & $69.3 \pm 7.8$ \\
\hline FEV $_{1} \mathrm{~L}$ & $1.08 \pm 0.47$ \\
\hline FEV1 \% pred & $45 \pm 18$ \\
\hline FVC L & $2.36 \pm 0.87$ \\
\hline BMI $\mathbf{k g} \cdot \mathbf{m}^{-2}$ & $26.2 \pm 6.3$ \\
\hline $\mathrm{Pa}, \mathrm{O}_{2} \mathrm{kPa}$ & $8.86 \pm 1.08$ \\
\hline $\mathrm{Pa}, \mathrm{CO}_{2} \mathrm{kPa}$ & $5.74 \pm 0.95$ \\
\hline Smoking pack-yr & $48.1 \pm 34.9$ \\
\hline SGRQ total score & $59.0 \pm 18.3$ \\
\hline \multicolumn{2}{|c|}{ 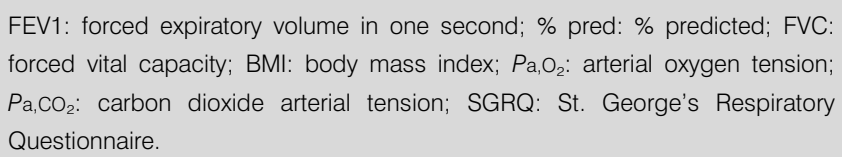 } \\
\hline
\end{tabular}




\section{Time course of airway and systemic inflammation at exacerbation of COPD}

The time course data for the inflammatory markers at exacerbation are reported in table 2 . There was a significant rise in serum IL-6, serum CRP and sputum IL-6 between baseline and onset of the exacerbation. The concentration of serum IL-6 measured at day 7 was significantly lower than that at baseline, reflecting the response to exacerbation therapy. By day 14, both airway and systemic inflammatory markers had returned to concentrations not significantly different from those present at baseline.

\section{Exacerbation recovery}

The median (IQR) symptom recovery time was 9 (4-18) days. In $23 \%$ of exacerbations, symptoms had not recovered to baseline by day 35 . There were no significant differences in clinical indices of nonrecovery between the frequent and infrequent exacerbators: e.g. nonrecovery of symptoms was $31 \%$ in frequent exacerbators versus $25 \%$ in infrequent exacerbators (Chi-squared $=0.28, p=0.60$ ). There was no significant difference in treatment with oral steroids at onset of the exacerbation between patients with recovered and nonrecovered exacerbations (Chi-squared $=1.02, \mathrm{p}=0.31$ ).

In a mixed linear model analysis, patients with nonrecovered exacerbations at day 35 had a persistently higher serum CRP (but not IL-6) concentration during the recovery period, compared with those patients who had recovered $(p=0.03)$. This is illustrated in figure 1.

Although there was no significant rise in sputum IL-8 at exacerbation onset, when each subject's exacerbation value is corrected for their own baseline, the magnitude of rise in IL- 8 was correlated with the symptom recovery time $\left(r_{s}=0.41\right.$, $\mathrm{p}=0.01$ ). Similarly, there were significant relationships between symptom recovery time and changes in sputum IL-6 and -8 between baseline and day 7 , probably reflecting the completeness of response to therapy. The greater the reduction in inflammatory marker, the shorter the recovery time, as illustrated in figure 2 (sputum IL-6: $r_{s}=0.57, p=0.004$; sputum IL-8: $\left.r_{s}=0.48, p=0.01\right)$. The symptom recovery time was not

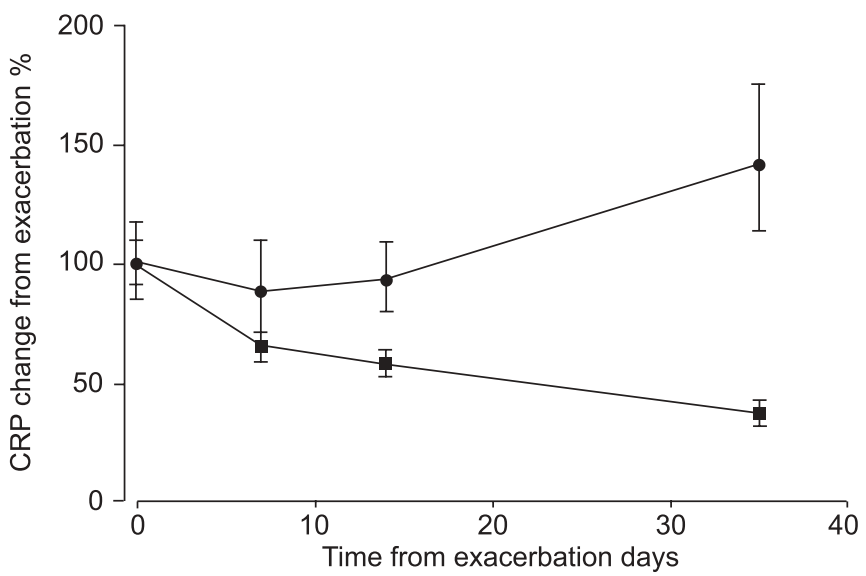

FIGURE 1. Time trend of serum C-reactive protein (CRP) in patients whose symptoms had recovered $(\boldsymbol{\square})$ and those whose symptoms had not recovered $(\boldsymbol{\bullet})$ at day $35(p=0.03)$. Estimates from the mixed linear model analysis on logtransformed data were anti-logged. Data are presented as mean \pm SEM expressed as a percentage of the value of the exacerbation onset sample (time $=0$ ).

related to the changes in sputum IL-6 or serum IL- 6 and CRP between baseline and exacerbation onset, or at any other timepoints during the recovery.

\section{Exacerbation frequency}

The time trends at exacerbation in serum IL-6 and CRP, between frequent and infrequent exacerbators, are illustrated in figures $3 a$ and $b$. Frequent exacerbators had a smaller reduction in systemic inflammation between exacerbation and day 35, despite treatment, compared with infrequent exacerbators. The evolution of serum IL-6 and CRP was significantly different between these groups (both $\mathrm{p}<0.05$ ). However, analysis of the baseline and exacerbation onset samples showed no significant difference in the percentage rise in serum CRP $(480 \%$ versus $443 \%$, $\mathrm{p}=0.42)$ or serum IL-6 $(245 \%$ versus $301 \%, \mathrm{p}=0.75$ ) between patients with frequent and infrequent exacerbations. There was a trend towards frequent

\section{TABLE 2 Time course of inflammatory markers at exacerbation of chronic obstructive pulmonary disease}

\begin{tabular}{|c|c|c|c|c|c|c|c|c|c|}
\hline Marker & Baseline & Exacerbation onset & $\begin{array}{c}\text { p-value } \\
\text { baseline- } \\
\text { onset }\end{array}$ & Day 7 & $\begin{array}{c}\text { p-value } \\
\text { baseline-day } \\
7\end{array}$ & Day 14 & $\begin{array}{c}\text { p-value } \\
\text { baseline-day } \\
14\end{array}$ & Day 35 & $\begin{array}{c}\text { p-value } \\
\text { baseline-day } \\
35\end{array}$ \\
\hline \multicolumn{10}{|l|}{ Sputum } \\
\hline $\mathrm{IL}-6 \mathrm{pg} \cdot \mathrm{mL}^{-1}$ & $\begin{array}{c}112 \\
(40-219)\end{array}$ & $\begin{array}{c}161 \\
(86-308)\end{array}$ & 0.03 & $\begin{array}{c}144 \\
(64-226)\end{array}$ & 0.31 & $\begin{array}{c}124 \\
(83-236)\end{array}$ & 0.95 & $\begin{array}{c}216 \\
(76-319)\end{array}$ & 0.63 \\
\hline \multicolumn{10}{|l|}{ Serum } \\
\hline $\mathrm{IL}-6 \mathrm{pg} \cdot \mathrm{mL}^{-1}$ & $\begin{array}{c}5.6 \\
(3.1-8.4)\end{array}$ & $\begin{array}{c}12.1 \\
(4.0-19.9)\end{array}$ & $<0.01$ & $\begin{array}{c}3.9 \\
(1.6-6.4)\end{array}$ & $<0.01$ & $\begin{array}{c}4.9 \\
(2.6-8.7)\end{array}$ & 0.16 & $\begin{array}{c}5.8 \\
(3.2-9.0)\end{array}$ & 0.38 \\
\hline $\mathrm{CRP} \mathrm{mg} \cdot \mathrm{L}^{-1}$ & $\begin{array}{c}6.5 \\
(3.8-11.8)\end{array}$ & $\begin{array}{c}10.9 \\
(5.5-34.2)\end{array}$ & $<0.01$ & $\begin{array}{c}5.3 \\
(3.5-9.4)\end{array}$ & 0.95 & $\begin{array}{c}4.0 \\
(2.3-9.6)\end{array}$ & 0.10 & $\begin{array}{c}6.8 \\
(3.6-11.6)\end{array}$ & 0.42 \\
\hline
\end{tabular}

Data are presented as median (interquartile range), unless otherwise stated. IL: interleukin; CRP: C-reactive protein. 

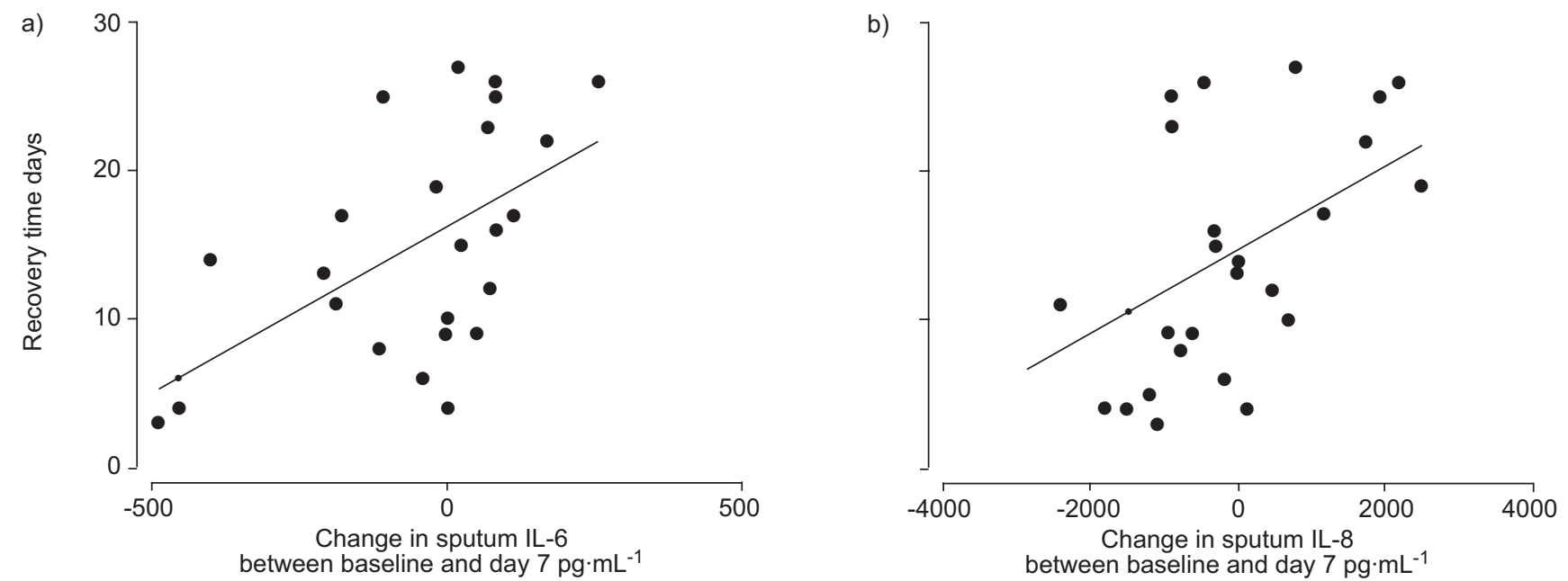

FIGURE 2. Relationship between exacerbation symptom recovery time and changes in a) sputum interleukin (IL)-6 ( $\left.r_{s}=0.57, p=0.004\right)$ and $\left.b\right)$ sputum IL-8 ( $r_{s}=0.48$, $p=0.01$ ) between baseline and day 7 , probably reflecting the completeness of response to therapy.
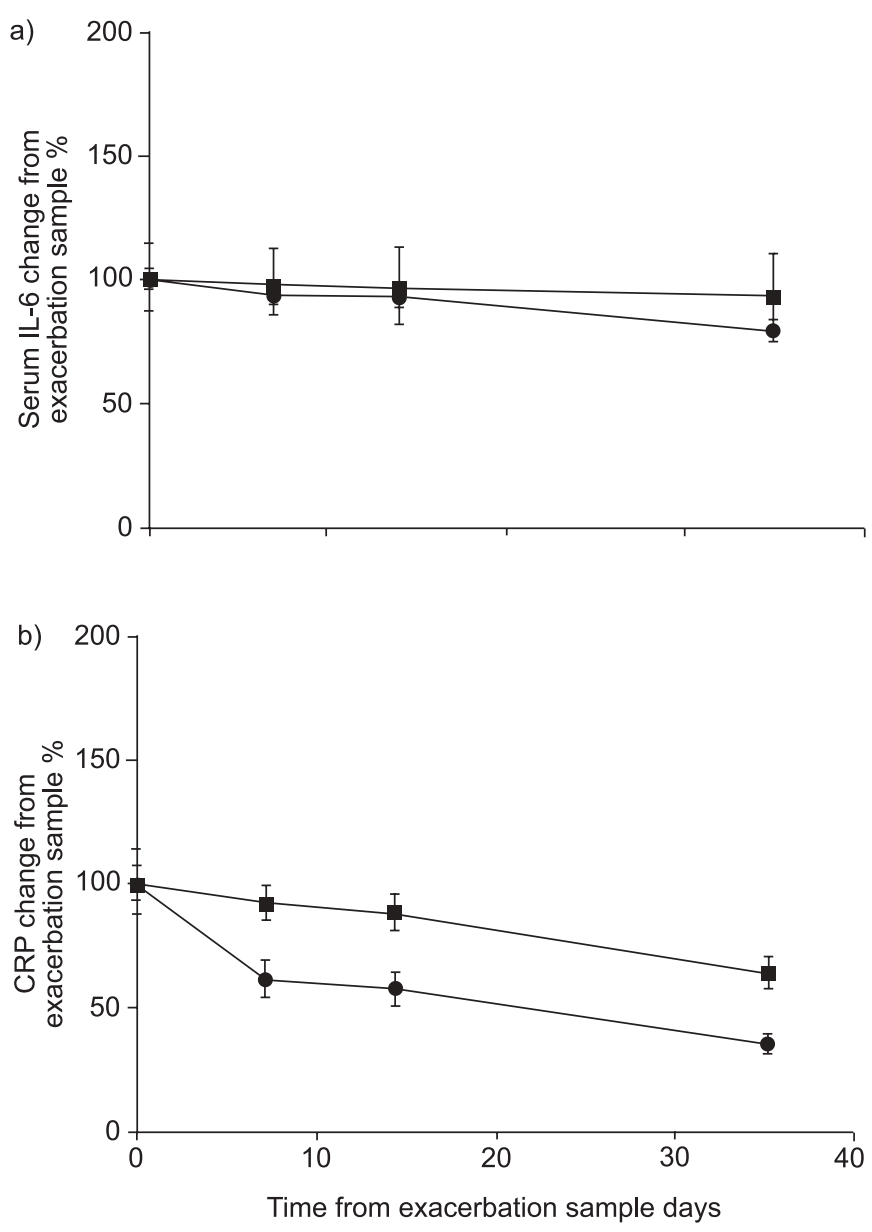

FIGURE 3. Time trend of a) serum interleukin (IL)-6 and b) serum C-reactive protein (CRP) at exacerbation of chronic obstructive pulmonary disease and during recovery, in frequent $(\boldsymbol{\square})$ and infrequent $(\bullet)$ exacerbators $(p<0.05)$. Estimates from the mixed linear model analysis on log-transformed data were anti-logged. The mean \pm SEM are expressed as a percentage of the value of the exacerbation onset sample (time $=0$ ). exacerbators being treated with oral steroids more often than infrequent exacerbators (Chi-squared $=2.86, \mathrm{p}=0.07$ ).

\section{Recurrent exacerbations}

In total, $22 \%$ of patients had a recurrent exacerbation within 50 days of the index exacerbation. These recurrent exacerbations were all treated exacerbations. Patients who presented with symptoms of a common cold at the first exacerbation were likely to present with a cold at the recurrent exacerbation (Chi-squared $=6.11$ and $p=0.01$ ). This relationship was not statistically significant for any of the other exacerbation symptoms. Patients who had a recurrent exacerbation had a significantly higher serum CRP concentration 14 days after the index exacerbation, compared with those who did not have a recurrent exacerbation: $8.8 \quad(4.4-15.9) \mathrm{mg} \cdot \mathrm{L}^{-1}$ versus 3.4 (2.1-5.5) $\mathrm{mg} \cdot \mathrm{L}^{-1}(\mathrm{p}=0.007$; fig. 4). In a multivariate analysis, $\mathrm{CRP}$ at day 14 was related to a recurrent exacerbation within 50 days independent of the disease severity, the exacerbation frequency and the treatment of the index exacerbation with oral steroids $(p=0.004)$. No such relationships were demonstrated for the other markers and time-points.

There were no significant relationships between recurrent exacerbations and the concentration of airway or systemic inflammatory markers in the stable state prior to the index exacerbation. The severity of the index exacerbation was also not related to the occurrence of recurrent exacerbations (total symptom score for nonrecurrent versus recurrent exacerbations was $3(2.0-3.7)$ versus $3(2-4)$, respectively $(\mathrm{p}=0.99)$, and percentage change FEV1 was $-4.8 \%$ (-11.6- -1.2\%) versus $-12.9 \%$ $(-14.1--6.6 \%), p=0.20)$.

\section{Time to next exacerbation}

The median (IQR) time to the next exacerbation was 93 (50178) days. Of the subsequent exacerbations, $75 \%$ were treated exacerbations. A higher CRP concentration 14 days after the index exacerbation was associated with a shorter time to the next exacerbation. This is illustrated in figure $5\left(r_{s}=-0.47, p<0.01\right)$. 


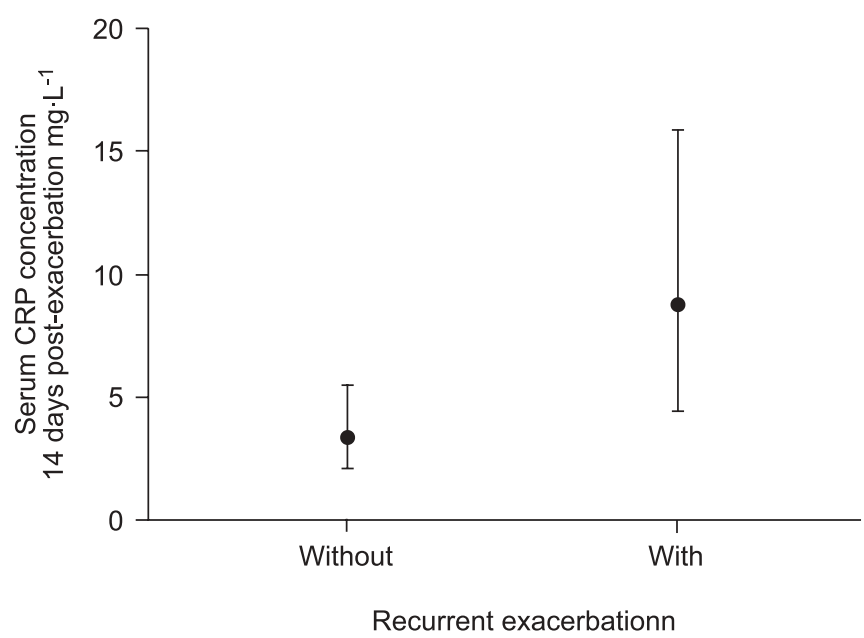

FIGURE 4. Differences in median \pm interquartile range serum C-reactive protein (CRP) concentration at day 14 between patients with and without a recurrent exacerbation within 50 days: $8.8 \mathrm{mg} \cdot \mathrm{L}^{-1}$ versus $3.4 \mathrm{mg} \cdot \mathrm{L}^{-1}(p=0.007)$.

\section{DISCUSSION}

The present study is the first to evaluate the time course of recovery in airway and systemic inflammatory markers at exacerbation of COPD, in a cohort of patients with wellcharacterised disease. The new and principal findings of the present study may be summarised as follows. 1) Assessment of serum CRP concentration 14 days after an exacerbation of COPD may be clinically important, as a relationship has been established between nonresolution of systemic inflammation and recurrent exacerbations within 50 days. 2) A direct relationship has been identified between symptom recovery time and the response of airway inflammation to exacerbation therapy. 3) It has been demonstrated, for the first time, that frequent exacerbators have a reduced response to therapy, which results in persistently higher systemic inflammatory markers and which may explain the greater decline in lung function observed in these patients. 4) Serum inflammatory markers were better predictors of nonrecovery and recurrent exacerbations than sputum inflammatory markers.

The present authors have studied the relationships between airway and systemic inflammatory markers, symptom recovery time, recurrent exacerbations and time to the next exacerbation in a prospectively followed cohort. All the patients recruited into the present study completed daily diary cards for changes in exacerbation symptoms and reported exacerbations to the study team as soon as possible after exacerbation onset. A unique feature of using daily diary cards is that precise data can be collected on the start and end of an exacerbation to accurately determine nonrecovery of symptoms and PEFR. In addition, the study design allowed sampling early in the time course of the exacerbation when the inflammatory markers reached their initial peak. All the initial exacerbation samples were taken before starting additional exacerbation treatment.

The present authors have previously shown that the recovery time of an exacerbation is an index of exacerbation severity [13] and that patients with a longer exacerbation recovery are more likely to have had a delay between exacerbation onset and treatment initiation [20]. The present authors' previous study [13] has also shown that a significant number of COPD exacerbations do not recover to baseline. In the present study, it was established, for the first time, that patients who do not recover to baseline have persistently higher serum CRP levels during the recovery period, thus suggesting that the systemic inflammatory response is an important marker of the recovery time and outcome of the exacerbation.

It is now recognised that exacerbation frequency is an important outcome in COPD, as patients prone to frequent exacerbations have impaired health status [1], reduced physical activity [2], increased lower airway bacterial colonisation [21] and a faster decline in lung function [3, 4, 22]. These frequent exacerbators also have increased airway inflammation in the stable state [5] and the present authors have recently reported that frequent exacerbators have a faster rise in systemic inflammation over time compared with infrequent exacerbators [23]. The present study established that patients who are frequent exacerbators have significantly higher levels of serum IL-6 and CRP during the recovery period of an exacerbation, and this may account for the increased morbidity and mortality seen in this group. The current authors have recently described that the increase in airway and systemic inflammation in stable COPD patients over time is directly linked to disease progression [23] and thus it can be extrapolated that this delayed recovery in inflammatory markers in frequent exacerbators may be one of the mechanisms underlying a faster FEV1 decline in this group [3, 4, 22]. The slower resolution of exacerbation inflammatory markers in the frequent exacerbator group may also explain the increased airway inflammation that was previously observed in the stable state [5]. In the present study a difference in recovery time between frequent and infrequent exacerbators was not seen, consistent with previous findings [13].

Although most COPD exacerbations are treated in the community, they are an important cause of hospitalisation and are responsible for $\sim 2.4 \%$ of all acute medical admissions [24]. Within the year after admission to hospital with an exacerbation, $63 \%$ of patients are readmitted at least once [14],

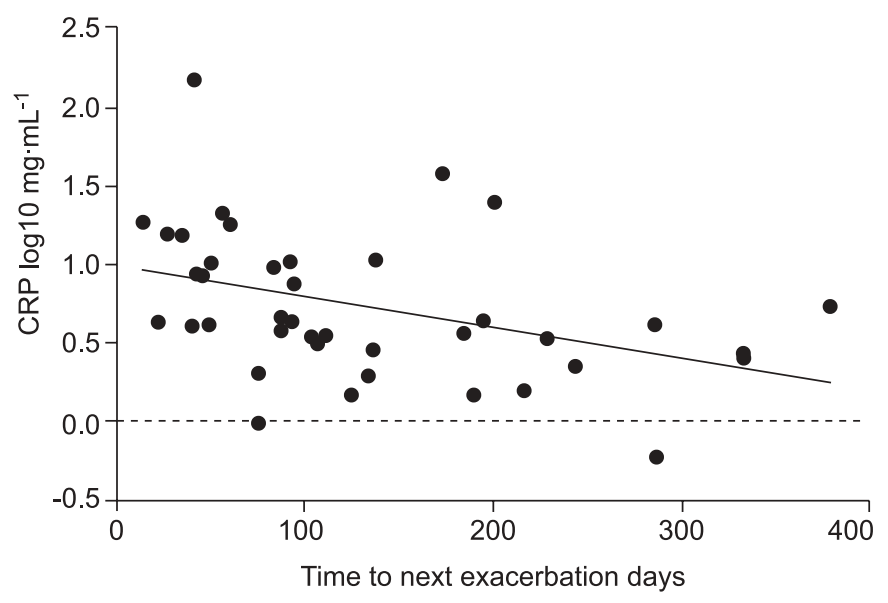

FIGURE 5. Relationship between serum C-reactive protein (CRP) concentration at day 14 of the index exacerbation and time to the next exacerbation $r_{s}=-0.47, p<0.01$ 
and this figure increased to $79 \%$ in patients admitted with acute hypercapnic respiratory failure [17]. These repeat admissions were mainly due to recurrent exacerbations and known risk factors for readmission include being a frequent exacerbator and having more severe COPD [14]. A recent study has reported that recurrent hospital admissions with COPD exacerbations are an independent risk factor for increased mortality [15]. Identification of patients likely to have a recurrent exacerbation early in the course of their index exacerbation may allow early implementation of appropriate preventive strategies and would be an important new approach in the management of this disease.

A further unique finding of the current study is the important association between raised serum CRP during the recovery period and recurrent exacerbations. These findings need to be explored further with interventional studies of therapies such as oral anti-inflammatory agents targeted at those patients with a high CRP concentration after exacerbation. Interventions used in this manner may be capable of preventing recurrent exacerbations. Reducing recurrent exacerbations would lead to substantial reductions in morbidity, mortality and healthcare costs.

The current authors have previously described that early presentation to healthcare professionals can affect the outcome of the exacerbation and reduce hospitalisation [20]. The present study emphasises the importance of following-up COPD exacerbations and this issue could be incorporated into COPD management guidelines. This might comprise, for example, routine follow-up at 14 days after the index exacerbation. Serum CRP can be easily and rapidly measured in many healthcare settings and can therefore be integrated into the routine follow-up of patients with COPD exacerbations without major additional cost.

A high CRP level despite treatment with antibiotics and steroids could be related to several factors, such as failure of the therapy prescribed at exacerbation to eradicate the causative agent or resistance of the responsible organism to the treatment prescribed. It may also be possible that heightened inflammatory status or modification of bacterial flora after the index exacerbation could facilitate infection by a different organism [25]. Change in the strain of bacteria colonising the lower airways has also been implicated in COPD exacerbations and strain changes may therefore be involved in exacerbation recurrence [26]. Comparing the nature of the index and recurrent exacerbation, only coryzal symptoms were found to be significantly associated with both events. This suggests that patients who develop recurrent exacerbations may be more susceptible to viral respiratory infections, consistent with a recent study from the present authors' group in which frequent exacerbators were more likely to acquire colds than infrequent exacerbators [27]. Further studies are required to evaluate the origin of the inflammatory response at a recurrent exacerbation.

COPD exacerbations are associated with increases in airway inflammation and IL- 8 is one of the markers of the neutrophilic inflammation found in this condition. Airway IL-8 concentration has been related to the degree of airflow obstruction [28], smoking status [29] and bacterial colonisation [30, 31]. An important finding from the present data was that the magnitude of the increase in sputum IL-8 at exacerbation was directly related to the symptom recovery time. A prolonged recovery time was also demonstrated in those patients who, despite treatment with antibiotics and steroids, had persistently high levels of sputum IL- 6 and IL-8 at day 7 compared with baseline. This is likely to reflect the failure to respond to the treatment prescribed at exacerbation. Therefore, relationships between the nonrecovery of airway inflammation and symptoms at exacerbation of COPD have been established here for the first time.

In conclusion, persistence of increased airway inflammation at exacerbation of chronic obstructive pulmonary disease is associated with a prolonged symptom recovery time. Heightened systemic inflammation is associated with recurrent exacerbations within 50 days. These results could form the basis for new therapeutic strategies to prevent recurrent exacerbations and delayed recovery. The present authors suggest that it is now important to incorporate into integrated chronic obstructive pulmonary disease care pathways both early presentation that improves the outcome of the exacerbation and adequate follow-up after the index event to reduce recurrent exacerbations. With these novel approaches the health burden of this important condition may be considerably reduced.

\section{REFERENCES}

1 Seemungal TA, Donaldson GC, Paul EA, Bestall JC, Jeffries DJ, Wedzicha JA. Effect of exacerbation of quality of life in patients with chronic obstructive pulmonary disease. Am J Respir Crit Care Med 1998; 157: 1418-1422.

2 Donaldson GC, Wilkinson TM, Hurst JR, Perera WR, Wedzicha JA. Exacerbations and time spent outdoors in chronic obstructive pulmonary disease. Am J Respir Crit Care Med 2005; 171: 446-452.

3 Kanner RE, Anthonisen NR, Connett JE. Lower respiratory illnesses promote FEV1 decline in current smokers but not ex-smokers with mild chronic obstructive pulmonary disease. Am J Respir Crit Care Med 2001; 164: 358-364.

4 Donaldson GC, Seemungal TAR, Bhowmik A, Wedzicha JA. Relationship between exacerbation frequency and lung function decline in chronic obstructive pulmonary disease. Thorax 2002; 57: 847-852.

5 Bhowmik A, Seemungal TAR, Sapsford RJ, Wedzicha JA. Relation of sputum inflammatory markers to symptoms and lung function changes in COPD exacerbations. Thorax 2000; 55: 114-120.

6 Wedzicha JA, Seemungal TA, MacCallum PK, et al. Acute exacerbations of chronic obstructive pulmonary disease are accompanied by elevations of plasma fibrinogen and serum IL-6 levels. Thromb Haemost 2000; 84: 210-215.

7 Crooks SW, Bayley DL, Hill SL, Stockley RA. Bronchial inflammation in acute bacterial exacerbations of chronic bronchitis: role of leukotriene $\mathrm{B}_{4}$. Eur Respir J 2000; 15: 274-280.

8 Gompertz S, O’Brien C, Bayley DL, Hill SL, Stockley RA. Changes in bronchial inflammation during acute exacerbations of chronic bronchitis. Eur Respir J 2001; 17: 1112-1119.

9 Drost EM, Skwarski KM, Sauleda J, et al. Oxidative stress and airway inflammation in severe exacerbations of COPD. Thorax 2005; 60: 293-300. 
10 Hurst JR, Perera WR, Wilkinson TMA, Donaldson GC, Wedzicha JA. Systemic and upper and lower airway inflammation at exacerbation of chronic obstructive pulmonary disease. Am J Respir Crit Care Med 2006; 173: 71-78.

11 Wilkinson TMA, Hurst JR, Perera WR, et al. Effect of interactions between lower airway bacterial and rhinoviral infection in exacerbations of COPD. Chest 2006; 129: 317-324.

12 Seemungal TAR, Harper-Owen R, Bhowmik A, et al. Respiratory viruses, symptoms, and inflammatory markers in acute exacerbations and stable chronic obstructive pulmonary disease. Am J Respir Crit Care Med 2001; 164: 1618-1623.

13 Seemungal TAR, Donaldson GC, Bhowmik A, Jeffries JD, Wedzicha JA. Time course and recovery of exacerbations in patients with chronic obstructive pulmonary disease. Am J Respir Crit Care Med 2000; 161: 1608-1613.

14 Garcia-Aymerich J, Farrero E, Felez MA, Izquierdo J, Marrades RM, Anto JM. Risk factors of readmission to hospital for a COPD exacerbation: a prospective study. Thorax 2003; 58: 100-105.

15 Soler-Cataluna JJ, Martinez-Garcia MA, Roman Sanchez P, Salcedo E, Navarro M, Ochando R. Severe acute exacerbations and mortality in patients with chronic obstructive pulmonary disease. Thorax 2005; 60: 925-931.

16 Roberts CM, Lowe D, Bucknell CE, Ryland I, Kelly Y, Pearson MG. Clinical audit indicators of outcome following admission to hospital with acute exacerbation of chronic obstructive pulmonary disease. Thorax 2002; 57: 137-141.

17 Chu CM, Chan VL, Lin AWN, Wong WY, Leung WS, Lai CKW. Readmission rates and life threatening events in COPD survivors treated with non-invasive ventilation for acute hypercapnic respiratory failure. Thorax 2004; 59: 1020-1025.

18 Jones PW, Quirk PH, Baveystock CM, Littlejohns P. A selfcomplete measure of health status for chronic airflow limitation. The St. George's Respiratory Questionnaire. Am Rev Respir Dis 1992; 145: 1321-1327.

19 Bhowmik A, Seemungal TAR, Sapsford RJ, Devalia JL, Wedzicha JA. Comparison of spontaneous and induced sputum for investigation of airway inflammation in chronic obstructive pulmonary disease. Thorax 1998; 53: 953-956.
20 Wilkinson TMA, Donaldson GC, Hurst JR, Seemungal TAR, Wedzicha JA. Early therapy improves outcomes of exacerbations of chronic obstructive pulmonary disease. Am J Respir Crit Care Med 2004; 169: 1298-1303.

21 Patel IS, Seemungal TAR, Wilks M, Lloyd-Owen SJ, Donaldson GC, Wedzicha JA. Relationships between bacterial colonization and the frequency, character, and severity of COPD exacerbations. Thorax 2002; 57: 759-764.

22 Dowson LJ, Guest PJ, Stockley RA. Longitudinal changes in physiological, radiological, and health status measurements in $\alpha_{1}$-antitrypsin deficiency and factors associated with decline. Am J Respir Crit Care Med 2001; 164: 1805-1809.

23 Donaldson GC, Seemungal TAR, Patel IS, et al. Airway and systemic inflammation and decline in lung function in patients with COPD. Chest 2005; 128: 1995-2004.

24 Hospital Episode Statistics, UK Department of Heath, 2003. www.dh.gov.uk/PublicationsAndStatistics/Statistics/ HospitalEpisodeStatistics/fs/en. Date last accessed: June 7, 2005.

25 Sethi S, File TM. Managing patients with recurrent acute exacerbations of chronic bronchitis: a common clinical problem. Curr Med Res Opin 2004; 20: 1511-1521.

26 Sethi S, Evans N, Grant BJ, Murphy TF. New strains of bacteria and exacerbations of chronic obstructive pulmonary disease. N Eng J Med 2002; 347: 465-471.

27 Hurst JR, Donaldson GC, Wilkinson TMA, Perera WR, Wedzicha JA. Epidemiological relationships between the common cold and exacerbation frequency in COPD. Eur Respir J 2005; 26: 846-852.

28 Yamamto C, Yoneda T, Yoshikawa M, et al. Airway inflammation in COPD assessed by sputum levels of interleukin-8. Chest 1997; 112: 505-510.

29 Hill AT, Bayley DL, Campbell EJ, Hill SL, Stockley RA. Airways inflammation in chronic bronchitis: the effects of smoking and $\alpha_{1}$-antitypsin deficiency. Eur Respir J 2000; 15 : 886-890.

30 Soler N, Ewig S, Torres A, Filella X, Gonzalez J, Zaubert A. Airway inflammation and bronchial patterns in patients with stable chronic obstructive pulmonary disease. Eur Respir J 1999; 14: 1015-1022.

31 Hill AT, Campbell EJ, Hill SL, Crooks S, Bayley DL, Stockley RA. Association between airway bacterial load and markers of airway inflammation in patients with stable chronic bronchitis. Am J Med 2000; 109: 288-295. 